\section{Culto ao corpo e uso de anabolizantes entre praticantes de musculação}

\author{
Body cult and use of anabolic steroids by \\ bodybuilders
}

\author{
${ }_{1}^{1}$ Instituto de Saúde Coletiva, \\ Universidade Federal da \\ Bahia, Salvador, Brasil. \\ Correspondência \\ J. A. B. Iriart \\ Instituto de Saúde Coletiva, \\ Universidade Federal da \\ Bahia. \\ Rua Augusto Vianna s/n, 2 o \\ andar, Campus Universitário \\ do Canela, Salvador, BA \\ 40110-060, Brasil. \\ iriart@ufba.br
}

\section{Abstract}

This study focused on the reasons for practicing bodybuilding and the use of anabolic steroids, as well as the social representations and uses of the body among bodybuilding steroid users. This ethnographic study involved participant observation in middle and lower-class bodybuilding gyms in Salvador, Bahia State, Brazil, and 43 in-depth interviews with steroid users. Aesthetic reasons are the main motivation for bodybuilding and steroid use in both middle and lowerclass users. Dissatisfaction with one's real body as compared to the ideal standard flaunted by the mass media, fear of being devalued or shunned by one's peer groups, the symbolic capital associated with a "pumped-up" body, and the sense of immediacy in obtaining results all contributed to steroid use. Preventive campaigns are needed, targeting young people and combining a critical view and deconstruction of the values assigned to the body by consumer society, counteracted by high-quality information on the health risks associated with anabolic steroid use.

Anabolic Agents; Exercise; Body Image
Jorge Alberto Bernstein Iriart 1

José Carlos Chaves ${ }^{1}$

Roberto Ghignone de Orleans 1

\section{Introdução}

Uma das facetas que tem caracterizado a sociedade de consumo contemporânea é a crescente importância atribuída à aparência corporal. Nas últimas décadas, o corpo tornou-se alvo de uma atenção redobrada com a proliferação de técnicas de cuidado e gerenciamento dos corpos, tais como dietas, musculação e cirurgias estéticas. Homens e mulheres investem cada vez mais tempo, energia e recursos financeiros no consumo de bens e serviços destinados à construção e manutenção do invólucro corporal. Por outro lado, alguns estudos mostram que em paralelo ao culto ao corpo tem aumentado a insatisfação das pessoas com seus corpos, assim como o consumo das chamadas "drogas da imagem corporal", entre as quais se incluem os esteróides anabólicos androgênicos ou anabolizantes 1 .

Os anabolizantes são substâncias sintetizadas em laboratório, relacionadas aos hormônios masculinos (androgênios). O consumo destas substâncias produz efeitos anabólicos, como o aumento da massa muscular esquelética, e efeitos androgênicos ou masculinizantes. O aumento do consumo não terapêutico dos anabolizantes, especialmente entre a população jovem, tem sido relatado por pesquisadores em vários países 2,3,4,5,6 constituindo-se em crescente problema de saúde pública. As altas taxas de consumo de esteróides entre os jovens apontam para uma mudança no perfil dos usuários. O uso de ana- 
bolizantes, que antes era restrito a atletas e fisiculturistas, popularizou-se entre os jovens não atletas que passaram a utilizá-los para fins estéticos. Segundo Evans 4, dois terços dos usuários de anabolizantes são praticantes recreativos de musculação.

Nos Estados Unidos, estimativas recentes indicam a existência de 3 milhões de usuários. De $2,7 \%$ a $2,9 \%$ dos jovens adultos americanos usaram anabolizantes pelo menos uma vez em suas vidas 4 . Outros estudos mostram que $4 \%$ a $6 \%$ dos estudantes do sexo masculino do Ensino Médio (high school) admitem ter usado anabolizantes em algum momento de suas vidas e que o uso por mulheres aumentou significativamente na última década 3 . Estudos realizados no Canadá, Suécia, Inglaterra, Austrália e África do Sul relataram prevalências entre escolares do Ensino Médio (high school) que variam de $1 \%$ a $3 \% 3$. Levantamentos realizados em academias de musculação revelam que a prevalência de uso destas drogas entre fisiculturistas é bastante alta, variando de $15 \%$ a $30 \% 4$.

No Brasil, o consumo para fins estéticos dos anabolizantes ainda é pouco estudado. Estudos qualitativos como os de Iriart \& Andrade 7 e Sabino 8 descrevem o grande consumo dessas substâncias, incluindo o uso de produtos veterinários, entre praticantes de musculação em Salvador (Bahia) e no Rio de Janeiro. Estudos quantitativos realizados em academias de musculação de São Paulo ${ }^{9}$, Porto Alegre (Rio Grande do Sul) 10 e Goiânia (Goiás) 11 encontraram altas prevalências do uso de anabolizantes (respectivamente, $19 \% ; 11,1 \%$ e $9 \%$ ).

O uso abusivo de anabolizantes está associado a vários efeitos colaterais nocivos à saúde $3,4,12,13$. No sistema reprodutivo masculino, o consumo de anabolizantes acarreta desequilíbrio hormonal com redução nos níveis de testosterona endógena podendo levar à ginecomastia, atrofia testicular, alterações na morfologia do esperma e infertilidade. Entre os efeitos dermatológicos, encontra-se a acne que, segundo Melnik et al. ${ }^{6}$, ocorre em $50 \%$ dos usuários de anabolizantes e é um importante indicador clínico do abuso dessas substâncias.

O uso de anabolizantes também tem sido relacionado com fatores de risco cardiovasculares, existindo relatos de casos de hipertensão, hipertrofia ventricular, arritmia, trombose, infarto do miocárdio e morte súbita 4 . A estrutura e função do fígado são alteradas pelo uso de anabolizantes podendo acarretar hepatite, hiperplasia e adenoma hepatocelular ${ }^{3}$. Os efeitos colaterais se acentuam com o consumo de altas doses por longos períodos de tempo. É importante ressaltar, no entanto, que o consumo de anabolizan- tes por mulheres e adolescentes, mesmo por um curto período, pode ocasionar efeitos colaterais irreversíveis ${ }^{4}$. Nas mulheres, tais efeitos incluem alterações na menstruação, engrossamento da voz, encolhimento dos seios, aumento da libido, crescimento de cabelos no corpo, e aumento do tamanho do clitóris 3 . Outro ponto a ser destacado é que os efeitos colaterais associados ao uso destes produtos por longos períodos, tanto em doses terapêuticas quanto suprafisiológicas, ainda são desconhecidos 4. Complicações decorrentes da aplicação de anabolizantes por via parenteral também podem causar sérios problemas de saúde, como inflamações, fibroses musculares, infecções e abscessos. Somam-se a estes efeitos adversos o risco de contrair o HIV, ou os vírus das hepatites B e C pelo uso de equipamentos não estéreis de injeção 12 .

Um volume crescente de literatura traz evidências também da associação entre o uso de anabolizantes e desordens psiquiátricas, como distúrbios de personalidade, depressão, mania, psicose, suicídio e aumento nos níveis de irritabilidade e agressividade podendo causar dependência $3,4,13$.

No Brasil, vários casos de danos à saúde causados pelo consumo de anabolizantes têm sido relatados 7,9,10, mas pouco tem sido feito para prevenção do uso dessas substâncias entre os jovens.

O presente estudo teve por objetivo investigar as motivações para a prática da musculação e para o uso de anabolizantes, assim como as representações e usos sociais do corpo entre usuários de anabolizantes que praticam musculação em academias de bairros populares e de classe média de Salvador.

\section{Culto ao corpo e sociedade de consumo}

Para compreender o consumo de anabolizantes faz-se necessário compreender o crescente culto ao corpo na sociedade de consumo contemporânea. Desde os estudos pioneiros de Marcel Mauss, a antropologia tem mostrado como o corpo constitui-se, em todas as culturas, em símbolo sobre o qual se inscrevem as normas culturais. Os padrões de beleza, os significados associados aos músculos ou ao corpo obeso transformam-se ao longo do tempo e refletem os valores centrais de cada contexto cultural. Nas sociedades tradicionais, as marcas sociais no corpo indicavam o pertencimento do nativo a determinada etnia e sua inserção no espaço social. O fato novo, contudo, para o qual chama atenção Marzano-Parisoli 14 é a amplitude do fenômeno de valorização do invólucro corporal e o reforço dos critérios esté- 
ticos e éticos de controle aplicados aos corpos na contemporaneidade.

Na sociedade contemporânea, marcada por valores como o consumismo, o individualismo, a busca do sucesso e o acúmulo de bens materiais, o corpo tornou-se também objeto de consumo. O consumismo permite aos indivíduos se situar socialmente mediante a possessão e acúmulo de capital material e simbólico 15. As mercadorias, os objetos, as roupas e o corpo enquanto objetos de consumo passam a dizer a "verdade" sobre o sujeito constituindo suas referências, sua autoestima, e sua identidade. A enorme valorização da aparência corporal inscreve-se num processo em que o corpo físico assume um papel fundamental na exteriorização da subjetividade e na construção das identidades. Esse processo foi potencializado pela mídia, que adquiriu enorme poder de influência sobre as pessoas na contemporaneidade, passando a ocupar um papel importante na disseminação de valores e padrões estéticos 16 e contribuindo para a criação de novas necessidades que, por sua vez, alimentam uma milionária indústria da estética que não cessa de se expandir.

Segundo Bourdieu 17, a relação com o corpo é uma forma de experimentar a posição do sujeito no espaço social, medida pela distância entre o corpo real e o corpo ideal legitimado pela sociedade. As marcas corporais, ou o conjunto de signos distintivos que constituem o corpo permitem distinguir os indivíduos e grupos na estrutura social. Para este autor, enquanto produtos sociais, as propriedades corporais são apreendidas através de categorias de percepção e de sistemas de classificação intimamente associados à inserção de classe dos agentes sociais.

\section{Metodologia}

Foi realizado um estudo qualitativo de natureza etnográfica com utilização de técnicas qualitativas, como entrevistas semi-estruturadas e observação participante em academias de musculação de bairros das camadas médias e populares de Salvador. O trabalho de campo desenvolveu-se num período de oito meses, durante os quais foram realizadas 43 entrevistas em profundidade com usuários de anabolizantes e sete com instrutores das academias. Dois roteiros semi-estruturados foram elaborados e utilizados como guias para as entrevistas. Por entrevistas em profundidade 18 entende-se o tipo de entrevista que encoraja a narrativa do entrevistado e favorece a livre expressão de suas concepções sobre o tema da entrevista (estruturando-o do seu ponto de vista) e cuja continui- dade da conversação é alimentada em razão das respostas dadas pelo entrevistado, possibilitando aprofundá-las com questões de seguimento (follow up questions). As entrevistas tiveram em média mais de uma hora de duração e foram gravadas e transcritas integralmente.

A observação participante foi realizada em uma academia num bairro de classe média e duas academias localizadas em bairros populares. A entrada em campo aconteceu a partir do contato com instrutores e responsáveis pelas academias. Os pesquisadores matricularam-se nas academias e passaram a freqüentá-las semanalmente, em diferentes horários e dias da semana de forma a conhecer suas rotinas e observar a dinâmica das interações sociais no seu interior. A observação nas academias incluiu as conversas informais com instrutores e praticantes de musculação antes, durante e depois das práticas dos exercícios, permitindo também a observação da relação dos praticantes entre si. Todas as observações foram registradas em diários de campo.

A observação participante com presença sistemática em campo permitiu o contato com os praticantes de musculação e a identificação de alguns usuários de anabolizantes. Foi utilizada também a técnica da bola de neve (snowball sampling), por intermédio da qual um entrevistado indica outro e assim sucessivamente. A técnica tem se mostrado útil na realização de entrevistas com pessoas envolvidas com atividades estigmatizantes (como a prostituição ou o uso de drogas ilícitas) por favorecer o acesso a pessoas que sem o contato pessoal poderiam recusar serem entrevistadas 19. Nas academias dos bairros populares, o acesso aos usuários de anabolizantes também foi facilitado pela mediação dos agentes comunitários da Aliança de Redução de Danos Fátima Cavalcante da Universidade Federal da Bahia (ARD-FC/UFBA) que realizam trabalho de redução de danos em bairros de Salvador com ações que incluem a troca de seringas entre usuários de anabolizantes.

Foram considerados usuários e selecionados para as entrevistas em profundidade praticantes de musculação de 18 a 35 anos que tenham feito uso em algum momento de suas vidas de esteróides anabolizantes. A escolha dos informantes buscou contemplar o critério da heterogeneidade dos consumidores levando em conta, além das diferenças de sexo, idade e classe social, o padrão de consumo e o tempo de uso de anabolizantes.

\section{Análise}

Como categoria analítica importante nesta pesquisa foi utilizado o conceito de representações 
sociais, entendido como "um tipo de saber socialmente negociado, contido no senso comum e na dimensão da vida cotidiana, que permite ao indivíduo uma visão de mundo e o orienta nos projetos de ação e nas estratégias que desenvolve em seu meio social" 20 (p. 25). Enquanto conhecimentos enraizados social e culturalmente 21 , as representações sociais só adquirem sentido e significado pleno no contexto sócio-cultural e situacional em que se manifestam 20. É importante frisar que não existe uma relação direta entre representações e comportamento individual. Enquanto código partilhado e culturalmente carregado, porém, as representações estabelecem disposições e motivações para a ação social.

A análise teve por objetivo evidenciar o código pelo qual se elaboram significações ligadas às condutas individuais e coletivas 21 , no caso, a prática da musculação e o uso de anabolizantes, interpretando os discursos e práticas em seu contexto sócio-cultural mais amplo.

Em um primeiro momento, as entrevistas e diários de campo foram lidos e relidos em uma "leitura flutuante" na busca de temas salientes, padrões recorrentes e discordantes, estruturas de relevância dos atores sociais, expressões idiomáticas e metáforas 22. Cada entrevista transcrita foi então analisada e códigos foram indutivamente elaborados para designação dos temas emergentes. Este processo possibilitou a construção das categorias empíricas (a exemplo dos "ideais de corpo" ou das categorias êmicas "malhar para modelo" ou "malhar para segurança”), e de seu confronto com as categorias analíticas (representações do corpo, usos sociais do corpo, representações da musculação e dos anabolizantes) na busca das inter-relações e interconexões 22 .

Para auxiliar o ordenamento, codificação e facilidade na recuperação dos dados, foi utilizado o programa de análise de dados qualitativos N.Vivo 2 (QRS International Pty, Doncaster, Austrália). Este programa permite a codificação dos dados das entrevistas e observações em categorias e possibilita imprimir relatórios específicos (por cada categoria), além de facilitar o acesso aos dados para a criação de subcategorias 23 .

\section{Considerações éticas}

O presente estudo foi aprovado pelo comitê de ética do Instituto de Saúde Coletiva da UFBA (processo $\mathrm{n}^{\circ}$. 044-05/CEP-ISC) e cumpriu todos os requisitos da Resolução $n^{\circ}$. 196/96 do Conselho Nacional de Saúde.

\section{Resultados}

Perfil dos usuários de anabolizantes entrevistados

Dos 43 usuários entrevistados, 27 freqüentavam academias em bairros populares e 16 academias em bairros de classe média e alta; eram 37 homens e seis mulheres. Entre as mulheres, apenas uma usuária freqüentava academia em bairro popular. O pequeno número de usuários do sexo feminino identificados para entrevista está de acordo com o encontrado na literatura, que mostra a preponderância do sexo masculino no consumo de anabolizantes. Os usuários de anabolizantes praticantes de musculação em academias de bairros de classe média alta possuem alta escolaridade. Dos dezesseis entrevistados, nove são estudantes universitários e três possuem curso superior completo. Já nas academias dos bairros populares os praticantes de musculação entrevistados se caracterizam pela baixa e média escolaridade. Dos 27 entrevistados, 13 tem o Ensino Fundamental incompleto; sete tem o Ensino Médio completo e apenas um está cursando o Ensino Superior.

\section{Substâncias mais utilizadas nas academias de bairros populares e de classe média}

Entre os usuários das academias em bairros de classe média, as substâncias mais utilizadas foram Durateston (proprionato/fenilproprionato/isocaproato/caproato de testosterona; Organon, Brasil), Deca-durabolin (decanoanato de landrolona; Organon, Brasil) e Winstrol (estanozolol; Zambon, Espanha). Foram mencionados também o Deposteron (cipionato de testosterona; Sigma Pharma, Brasil), Primobolan (metenolona; Shering, México/Espanha/Alemanha), Hemogenin (oximetalona; Sanofi-Aventis, Sarsa/Hoechst Marion Roussel, Brasil) e produtos veterinários como Androgenol (testosterona animal; Hertape, Brasil) e ADE (complexo vitamínico; Labovet, Hertape e Pfizer, Brasil). Entre os usuários das academias dos bairros populares, as substâncias mais utilizadas foram Durateston, ADE e Deca-durabolin, seguidas de Estradon-p (testosterona e estradiol; Organon, Brasil), Hemogenin, Estigor (nandrolona animal e ADE; Burnet, Argentina), Potenay (complexo vitamínico veterinário e estimulante; Fort Dodge, Brasil), e Deposteron. Chama a atenção entre os usuários das academias dos bairros populares o grande consumo em doses muito elevadas de produtos veterinários, sendo os principais: o ADE, Androgenol, Estigor, Potenay e Equipoise ou Equifort (undecilenato de boldenona; $\mathrm{Pu}$ - 
rina, Brasil). Os anabolizantes utilizados, em geral, são os que têm os preços mais acessíveis, enquanto os usuários de classe média recorrem freqüentemente a produtos importados e mais dispendiosos como o anabolizante Winstrol. Os anabolizantes Durateston e Deca-durabolin, no entanto, encontram-se entre os produtos mais utilizados tanto por usuários de classe média quanto das classes populares.

\section{A busca do corpo ideal}

A preocupação com a estética foi sem dúvida a principal motivação referida pelos usuários, tanto nas academias dos bairros populares como nas academias de classe média, para o início da prática da musculação. Os resultados indicam que a preocupação com o invólucro corporal e a crescente obsessão com a forma física não se restringem apenas aos estratos sociais mais elevados. A busca da construção de um corpo adequado aos padrões valorizados na sociedade contemporânea, e difundidos pela mídia, dissemina-se pelas diferentes camadas sociais fazendo-se presente nas dispendiosas academias da elite soteropolitana como nas precárias e improvisadas academias dos bairros populares da cidade.

"Eu comecei a malhar pra ficar com um corpinho legal" (sexo masculino, 18 anos, classes populares).

"Eu tava preocupado em estética, assim, ter corpo bonito, sarado..." (sexo masculino, 22 anos, classes populares).

O modelo de corpo perseguido pelos praticantes de musculação se caracteriza pela musculatura saliente e definida e pela quase ausência de adiposidade. "Definir a musculatura" é a expressão mais recorrente nos discursos dos entrevistados e remete ao cuidadoso trabalho de tonificação e delineamento dos músculos: "Corpo dividido é assim: você vê que tem pessoas que esticam a perna e você vê os cortes. Então aí é uma perna dividida. Por que, além de ser grande, você vê os cortes... Igual o braço. Você puxa aqui, tem bíceps, puxa ali e então o tríceps é definido. Então você tem o ombro... O ombro você puxa assim e vê os cortes. O peito você olha assim e não vê aquele peito gordo, você vê um peito definido. Então um corpo dividido, é um corpo desenhado, os músculos são desenhados" (30 anos, sexo masculino, classes populares).

A gordura é vista como a grande vilã no caminho do corpo perfeito e o objetivo é erradicá-la por completo.

P: "E que tipo de corpo você deseja obter com a musculação?”.
R: "Um corpo definido sem, sem gordura, o mínimo de gordura” (25 anos, sexo masculino, classe média).

R: "Um corpo sem gordura, abdômen zero, a musculatura do abdômen tudo desenhado" (29 anos, sexo feminino, classe média).

Chama a atenção nos discursos, a freqüente alusão à busca de um ideal de perfeição corporal. Fala-se em "corpo perfeito" e acredita-se ser possível atingir este ideal no qual o desenvolvimento de uma musculatura trabalhada é uma das principais características. A possessão do corpo ideal é vista pelos entrevistados como condição importante para aumentar sua auto-estima e sentir-se bem consigo mesmo.

“Eu espero um bom resultado, modelar meu corpo, definir meu corpo. Eu ainda não cheguei onde eu quero. Eu preciso de mais... entendeu? Então, eu quero chegar à perfeição" (32 anos, sexo masculino, classe média).

P: "E o que é a perfeição pra você?".

R: "É o corpo todo simétrico, todo na medida certa, com tudo correto, compatível com o que se deseja" (32 anos, sexo masculino, classe média).

O descompasso entre o "corpo real" e o padrão de perfeição corporal idealizado gera grande insatisfação com o próprio corpo: "Eu era um pouco raquítico..., então eu entrei na malhação buscando dar uma melhorada no meu corpo..." (30 anos, sexo masculino, classes populares).

"Eu me achava muito magra, eu queria ganhar corpo" (25 anos, sexo feminino classe média).

É interessante notar a transformação nos significados do corpo musculoso, que no passado além de associar-se ao poder masculino, denotava também o trabalho manual e a condição proletária ${ }^{14}$. Na contemporaneidade, entretanto, o músculo perde esta última conotação e se torna ícone cultural altamente valorizado, simbolizando vigor, saúde e sucesso 14,24. Mais do que isso, o corpo musculoso adquire também um valor moral por meio do qual as pessoas passam a ser classificadas e julgadas: "Hoje em dia se você não tiver um corpo malhado, se você for fora de forma, as pessoas não tem o mesmo respeito por você" (29 anos, sexo feminino, classe média).

A imposição do ideal de corpo contemporâneo é claramente percebida como coercitiva por alguns informantes, sobretudo os mais jovens, que sofrem a pressão de seu grupo de pares para se adequarem aos padrões normativos: "Eu era muito magro... as pessoas ficavam fazendo críticas... diziam que eu era magro, que eu era seco, que eu era carcaça, que eu tinha que tomar 'bomba' pra sair daquilo. Eu era muito cobrado. A sociedade impõem isto, esse padrão de estética" (23 anos, sexo masculino, classe média). 
"Se você tem o seu corpo legal, bonitinho, te ajuda em muitas coisas. Você tem que ser magro, ou então ter o corpo definido, entendeu? Se você tiver fora desse padrão, você já é visto como diferente. Eu sei que é, assim que eu to sendo igual a todo mundo, o que a cultura atual quer" (22 anos, sexo masculino, classe média).

O medo de ser diferente, desvalorizado ou de não obter sucesso junto ao sexo oposto mobiliza as pessoas, particularmente os mais jovens à prática da musculação. O sucesso na aquisição de um corpo mais adequado aos padrões vigentes, por outro lado, recompensa aqueles que passam a se destacar pela presença física e conquistar o reconhecimento de seus pares. É muito forte nos discursos o desejo de atrair o olhar do outro: " $a$ gente acaba malhando para o outro, para mostrar os músculos".

O culto da aparência esta baseado na construção de um corpo para ser visto, o que Le Breton 25 denomina de estética da presença, sendo a musculatura desenvolvida um dos modos privilegiados de visibilidade do corpo no anonimato urbano 24

\section{Estética e saúde}

Menos importante que a motivação estética, mas igualmente presente nas justificativas dos usuários de anabolizantes para a prática da musculação é o "discurso da saúde" que enaltece as conseqüências positivas para a saúde advindas da musculação. Este discurso perpassa as diferentes camadas sociais e caracteriza-se também pela preocupação com o envelhecimento e o desejo de manter-se eternamente jovem: "quero chegar aos 40, 50 anos com cara de 20. Porque é bom para saúde, fortalece os ossos, fortalece o tecido, ajuda no batimento cardíaco, redução de algumas doenças cardiovasculares, pressão alta..." (31 anos, sexo masculino, classes populares).

"É obter um envelhecimento saudável. Porque através da musculação, quanto mais você envelhece, seu corpo precisa da massa muscular. Então, é melhor porque você não vai apresentar nenhum risco, coração, cardíaco, coisas assim. Você está com seu corpo forte. Envelhece na idade, mas o corpo continua novo" (31 anos, sexo masculino, classes populares)

É interessante notar que a preocupação com a saúde, manifesta na justificativa para a prática da musculação, não impede o uso de anabolizantes. Contribui para este fato a representação, similar ao relatado por Luz 26 em estudo no Rio de Janeiro, de que manter o "corpo em forma" torna-se cada vez mais equivalente a ter um corpo saudável. A aparência corporal revela o estado de saúde do indivíduo e o corpo trabalhado passa a ser indicador importante de boa saúde.

Para alguns usuários entrevistados nas academias populares, o discurso da saúde engloba o fato de a prática da musculação e o cuidado com o corpo favorecerem o afastamento de vícios como fumar e beber, tanto quanto o consumo de outras drogas percebidas como mais nocivas à saúde que os anabolizantes: "para nós que vivemos em um meio que não é muito favorável ao nosso desenvolvimento... [a musculação] me afastou do uso de tóxicos... me ajudou a me afastar da marginalidade que há no meu bairro" (22 anos, sexo masculino, classes populares).

\section{Representações e usos sociais do corpo}

Um dos principais núcleos de sentido no discurso dos entrevistados é a representação do corpo como um objeto incompleto, que necessita ser construído, trabalhado e aperfeiçoado. O corpo é concebido como um objeto plástico no qual o indivíduo pode e deve trabalhar, controlando-o e moldando-o segundo sua vontade.

"Eu tô completando meu corpo" (30 anos, sexo masculino, classes populares).

"Para mostrar que eu posso fazer o que eи quero" (29 anos, sexo masculino, classes populares).

"Eu tô conquistando o corpo que eu desejo" (23 anos, sexo feminino, classe média).

O processo de construção e de controle do corpo torna-se extremamente valorizado, distinguindo as pessoas "que se cuidam" das "pessoas desleixadas" que não investem em seus corpos. Como afirma Marzano-Parisoli 14 (p. 37), na contemporaneidade o corpo deve estar completamente "sob controle" e "é o corpo musculoso que dá a prova mais importante da capacidade que se tem de dominar a própria vida". Já um corpo gordo e flácido é julgado com desprezo, pois indica a falta de determinação no cuidado de si e, portanto, fraqueza moral. O processo de metamorfose e reconstrução do corpo é fundamental na ideologia do bodybuilding 24 . No fisiculturismo, o invólucro corporal torna-se alvo de uma atenção obsessiva, que implica enorme autodisciplina aproximando-se de um culto profano com ritos quase religiosos 24 . A prática da musculação adquire contornos ascéticos em que o esforço, o sacrifício e a dor sentida pelo praticante no processo de construção corporal são valorizados e atestam a sua superioridade moral, fato corroborado por um dos nossos informantes ao afirmar que: "a pessoa que tem o corpo grande demonstra que é superior".

Na contemporaneidade, o corpo passou a desempenhar um papel essencial na promoção individual, transformando-se em um objeto de 
consumo e de investimento. Como mostra Courtine ${ }^{24}$, sustentados pela obsessão dos invólucros corporais, consolidaram-se, a partir dos anos 80 do século XX, verdadeiros impérios industriais que englobam academias de musculação, revistas especializadas, suplementos alimentares, aparelhos de musculação e regimes alimentares. A beleza e a força física tornaram-se mercadorias altamente valorizadas e o indivíduo assumiu o papel de gestor do seu corpo 24 , que deve ser administrado como um capital 17,25.

Para os entrevistados freqüentadores de academias de classe média, o investimento no corpo ganha a forma, sobretudo do acúmulo de capital simbólico. A possessão do corpo midiático proporciona status à pessoa, que conquista admiração e popularidade no seu meio social, permitindo também a conquista afetiva de pares com mesmo nível de beleza. Entre os indivíduos entrevistados pertencentes às classes populares o trabalho sobre o corpo assume a conotação de um forte investimento profissional. Este aspecto fica bem evidenciado nas categorias êmicas "malhar para modelo ou malhar para segurança" utilizada por um dos informantes para fazer referência ao tipo de corpo que se deseja construir e às possibilidades de inserção no mercado de trabalho, ou mesmo de ascensão social por intermédio do trabalho sobre o corpo. Malhar para modelo tem como objetivo desenvolver moderadamente a musculatura construindo um corpo definido, mas não excessivamente musculoso. Para os entrevistados, a boa aparência proporcionada pelo corpo modelado é vista como um quesito que conta na busca da colocação no mercado de trabalho. Já "malhar para segurança" implica hipertrofiar a musculatura exageradamente, construindo um corpo enorme que imponha respeito ao simples olhar. Foi muito freqüente, no discurso dos praticantes de musculação nas academias populares o desejo de construir um corpo de fisiculturista, exageradamente musculoso. Nomes como Ronnie Coleman e Arnold Schwarzenegger são muito citados como modelos de corpo admirados pelos entrevistados. Muitos dos praticantes de musculação nas academias populares trabalham ou fazem bicos como segurança sendo esta ocupação, em um contexto de forte desemprego, a principal opção para inserção no mercado de trabalho.

“...Eu nunca, nunca tive um trabalho certo, hoje em dia eu já tenho. Não tenho de carteira assinada, mas tenho um trabalho, agradeço ao meu corpo porque, eu tenho uma estatura, eu trabalho de segurança então, o pessoal já me visualiza mais... por ter porte bonito. Foi aí que minha vida começou a mudar, depois da musculação" (30 anos, sexo masculino, classes populares).
“...Porque quando você tem um corpo avantajado com malhação, você é chamado para trabalhar em eventos, você tem vários lugares para trabalhar" (31 anos, sexo masculino, classes populares).

A hipervirilização do corpo associa-se também à construção de um ideal de masculinidade hegemônica 27, bem expresso na fala de um entrevistado que afirmou a importância dos músculos para "impor sua masculinidade". A musculatura hiperdesenvolvida atesta de forma inequívoca a masculinidade do fisiculturista. Autores como Klein 28, Courtine 24, e Le Breton 25 vêem na hipervirilização uma resposta à ameaça que representa um sentimento de perda da potência viril na redefinição dos papéis de gênero. A carapaça de músculos refletiria a insegurança em um mundo no qual as relações de gênero estão em rápida transformação e o papel masculino tradicional é cada vez mais questionado.

A imagem de sucesso associada a celebridades com corpos musculosos disseminada pelos meios de comunicação de massa é uma importante fonte de motivação para a modificação corporal. Na lógica do consumo, a mídia contribuiu para expansão do consumo de bens e produtos de beleza e transformou a aparência numa dimensão essencial na constituição da identidade e da subjetividade, enquanto importante componente da personalidade e do bem estar dos indivíduos 16,29. Como afirma Costa 29 (p. 166): "estar feliz não se resume mais a se sentir sentimentalmente repleto. Agora é preciso também se sentir corporalmente semelhante aos 'vencedores....". Para este autor 29 , a massa dos indivíduos é levada a admirar e a querer imitar o estilo de vida dos ricos, poderosos e famosos. Dada, no entanto, a dificuldade que a maioria tem de ascender socialmente, o corpo aparece como o principal instrumento passível de possibilitar ao indivíduo comum aproximar-se de alguma forma do círculo dos privilegiados. A corrida pela posse do corpo midiático, do corpo-espetáculo, conquistando uma imagem semelhante aos dos bens sucedidos representaria um meio de aceder simbolicamente a uma condição social da qual a maioria da população está excluída 29. Na mesma linha interpretativa, Le Breton 25 afirma que modifica-se o corpo na impossibilidade de modificar suas condições de existência. "Ao mudar o corpo, o indivíduo pretende mudar sua vida, modificar seu sentimento de identidade" 25 (p. 30). O corpo tornou-se um acessório da pessoa e ao perceberse cada vez mais enquanto reflexo de seu invólucro corporal, o indivíduo busca reduzir, pelo trabalho sobre o corpo, o desvio experimentado entre sua aparência e seu eu-interior. Neste processo, a interioridade do sujeito encontra-se em 
constante esforço de exteriorização, reduzindose a sua superfície corporal 25 .

\section{Razões para o uso de anabolizantes}

A motivação primeira para o uso de anabolizantes é o imediatismo na obtenção do corpo desejado. Busca-se o rápido aumento de massa e definição muscular. No dizer de um informante: "conseguir em 3 meses o que conseguiria em 3 anos". A insatisfação com a lentidão do crescimento muscular na musculação "natural" ou a sensação de que está malhando, mas não está desenvolvendo musculatura foi trazida por alguns informantes como razão para o uso de anabolizantes. A comparação com colegas de academia que começaram a praticar musculação ao mesmo tempo e apresentaram rápido desenvolvimento muscular aparece como estímulo para o consumo, fortalecido pela cultura de uso de anabolizantes disseminada entre grupos que freqüentam as academias. Em uma das academias de um bairro popular em que foi realizada observação participante foi possível observar o uso explícito de anabolizantes. Os próprios praticantes aplicavam uns nos outros injeções de Durateston e ADE antes de iniciar a malhação. Na lixeira do banheiro da academia, a grande quantidade de seringas e agulhas descartáveis utilizadas atestava o grande consumo de anabolizantes. Os anabolizantes eram tema freqüentes de conversações e brincadeiras entre os praticantes de musculação.

Já os freqüentadores de academias de classe média e alta tendem a ocultar o seu uso, que é feito fora do espaço da academia, mostrandose também mais reservados nas conversas sobre o consumo de anabolizantes. A maior parte dos instrutores de academias entrevistados condenou o uso de anabolizantes, enfatizando os efeitos danosos à saúde. Alguns, contudo, fazem ou já fizeram uso de esteróides. Um personal trainer justificou o uso de anabolizantes afirmando que necessita possuir um corpo musculoso e definido, pois assim consegue aumentar o número de alunos interessados em realizar aula particular. O seu corpo funcionaria como um espelho, refletindo o modelo de corpo no qual o aluno se inspiraria na busca de seus objetivos. Nas academias mais precárias dos bairros populares é comum que o instrutor seja autodidata. Em uma das academias na qual se realizou a observação participante o papel de instrutor era assumido por praticantes de musculação veteranos que orientavam os novatos.

Para os jovens, o pertencimento ao grupo de amigos é uma faceta fundamental de sua identidade e vários usuários entrevistados relataram o incentivo de amigos, namorados(as) e colegas de academia como um fator que favoreceu o uso de anabolizantes. O medo de ser desvalorizado entre os seus pares ou até mesmo de ser excluído do grupo favorece que o jovem busque se adequar ao padrão de corpo socialmente valorizado e acompanhe o comportamento do grupo no uso dos anabolizantes.

“Tomei só de onda, os outros tomando, fui na pilha e tomei também" (18 anos sexo masculino, classes populares).

"Eu via as pessoas se aplicando, aí comecei a me injetar também" (20 anos, sexo masculino, classes populares).

Entre os usuários das classes populares, os anabolizantes aparecem também como meio mais barato de construção do corpo ideal na ausência de recursos financeiros para comprar suplementos alimentares e manter uma alimentação adequada.

"E eu tomava suplemento alimentar tudo e não via nenhum [resultado], era caro, né? Complicado pra mim e o anabolizante era mais barato o efeito era rápido aí eu resolvi usar" (18 anos, sexo masculino, classes populares).

Para alguns entrevistados, particularmente os que desejam hipertrofiar exageradamente o corpo, os anabolizantes são a droga que permite ultrapassar os limites fisiológicos na perseguição do corpo ideal.

"Eu já malho há algum tempo. Eu percebi que eu cheguei num platô, não saia dali, eu queria mais. Então, anabolizante me proporcionou, pegar mais peso" (25 anos, sexo masculino, classe média).

Muitos entrevistados referiram não ter energia para malhar sem a utilização de anabolizantes. A musculação destituída de ajuda química torna-se um sacrifício pouco recompensante. Este fato, somado à rápida perda muscular quando se interrompe o uso dos anabolizantes, faz com que muitos usuários prolonguem o uso das drogas correndo o risco de tornarem-se dependentes: “...as pessoas pararam de me elogiar, pararam de me olhar. Então eu tenho que voltar a fazer minha musculação, tenho que voltar a ter meu corpo, tenho que crescer novamente. Aí tem aquele negócio do vício, né. Aí toma [anabolizante], aí sempre quer mais, quase sempre se convence de que não tá suficiente, não tá legal, não tá bom, e aí, desenfreia" (22 anos, sexo masculino, classes populares).

\section{Conclusões}

Os resultados do estudo mostram que a principal razão para a prática da musculação e para o 
consumo de anabolizantes, tanto entre usuários de classe média como das classes populares, é a motivação estética, fato que tem sido constatado em estudos realizados em outras capitais brasileiras 8,9,10. A insatisfação com corpo real em comparação ao padrão ideal disseminado pela mídia, o receio de ser excluído do grupo de pares ou de ser desvalorizado, associado a um discurso que associa saúde a "estar em forma" e o imediatismo na obtenção do corpo desejado favorecem o uso de anabolizantes. Na contem- poraneidade, o corpo tornou-se um objeto de consumo e de investimento, e os anabolizantes são vistos como as drogas que permitem conquistar rapidamente o corpo ideal. Os resultados apontam a necessidade de realização de campanhas de prevenção voltadas aos jovens e centradas, de um lado, na visão crítica e na desconstrução dos valores associados ao corpo na sociedade de consumo, e de outro, na veiculação de informação de qualidade sobre os riscos à saúde no consumo de anabolizantes.

\section{Resumo}

O objetivo do estudo foi investigar as motivações para a prática da musculação e uso de anabolizantes, assim como as representações e usos sociais do corpo entre usuários de anabolizantes praticantes de musculação. Foi realizado um estudo etnográfico com observação participante em academias de musculação de bairros de classe média e classes populares de Salvador, Bahia, Brasil, e realização de 43 entrevistas em profundidade com usuários de anabolizantes. A prática da musculação e o uso de anabolizantes, tanto entre usuários de classe média quanto populares, são motivados sobretudo por razões estéticas. A insatisfação com corpo real em comparação ao padrão ideal disseminado pela mídia, o receio de ser desvalorizado ou excluído do grupo de pares, o capital simbólico associado ao corpo "trabalhado" e o imediatismo na obtenção dos resultados favorecem o uso de anabolizantes. Faz-se necessária a realização de campanhas de prevenção voltadas para os jovens que aliem a visão crítica na desconstrução dos valores associados ao corpo na sociedade de consumo à veiculação de informação de qualidade sobre os riscos à saúde no consumo de anabolizantes.

\section{Colaboradores}

J. A. B. Iriat participou da elaboração do projeto, coordenação da equipe no trabalho de campo, análise dos dados e redação do artigo. J. C. Chaves e R. G Orleans participaram do trabalho de campo, análise de dados e redação do artigo.

\section{Agradecimentos}

Financiado pelo Conselho Nacional de Desenvolvimento Científico e Tecnológico (CNPq - processo $\mathrm{n}^{\circ}$. 480742/2004-9 Edital Universal). R. G. Orleans contou com bolsa de iniciação científica da Fundação de Amparo à Pesquisa do Estado da Bahia (PIBIC/FAPESB) durante a realização do estudo. 


\section{Referências}

1. Kanayama G, Pope HG, Hudson JI. Body image drugs: a growing psychosomatic problem. Psychother Psychosom 2001; 10:61-5.

2. Kanayama G, Pope HG, Cohane G, Hudson JI. Risk factors for anabolic-androgenic steroid use among weightlifters: a case-control study. Drug Alcohol Depend 2003; 71:77-86.

3. Bahrke MS, Yesalis CE. Abuse of anabolic androgenic steroids and related substances in sport and exercise. Curr Opin Pharmacol 2004; 4:614-20.

4. Evans NA. Current concepts in anabolic-androgenic steroids. Am J Sports Med 2004; 23:534-42.

5. Cafri G, Thompson JK, Ricciardelli L, McCabe M Smolak L, Yeasils C. Pursuit of the musuclar ideal: physical and psychological consequences and putative risk factors. Clin Psychol Rev 2005; 25: 215-39.

6. Melnik B, Jansen T, Grabbe S. Abuse of anabolicandrogenic steroids and bodybuilding acne: an underestimated health problem. J Dtsch Dermatol Ges 2007; 5:110-7.

7. Iriart JAB, Andrade TM. Musculação, uso de esteróides anabolizantes e percepção de risco entre jovens fisiculturistas de um bairro popular de Salvador, Bahia, Brasil. Cad Saúde Pública 2002; 18:1379-87.

8. Sabino C. Anabolizantes: drogas de Apolo. In: Goldenberg M, organizador. Nu \& vestido. Dez antropólogos revelam a cultura do corpo carioca. Rio de Janeiro: Editora Record; 2002. p. 139-88.

9. Silva ISMF, Moreau RLM. Uso de esteróides anabólicos androgênicos por praticantes de musculação de grandes academias da cidade de São Paulo. Rev Bras Ciênc Farm 2003; 39:327-33.

10. Silva PRP, Machado LC, Figueiredo VC, Cioffi AP, Prestes MC, Czepielewski MA. Prevalência do uso de agentes anabólicos em praticantes de musculação de Porto Alegre. Arq Bras Endocrinol Metab 2007; 51:104-10.

11. Araújo LR, Andreolo J, Silva MS. Utilização de suplemento alimentar e anabolizante por praticantes de musculação nas academias de Goiânia-Go. Rev Bras Ciênc Mov 2002; 10:13-8.

12. Rich JD, Dickinson BP, Feller A, Pugatch D, Mylonakis E. The infectious complications of anabolic-androgenic steroids injection. Int J Sports Med 1999; 20:563-6.

13. Pope HG, Katz DL. Psychiatric effects of exogenous anabolic-androgenic steroids. In: Wolkowitz $\mathrm{O}$, Rothschild A, editors. Psychoneuro-endocrinology. Washington DC: American Psychiatric Publishing; 2003. p. 331-58.
14. Marzano-Parisoli MM. Pensar o corpo. Petrópolis: Editora Vozes; 2004.

15. Kemp K. Corpo modificado, corpo livre? São Paulo: Paulus; 2005.

16. Goldenberg M. A civilização das formas: o corpo como valor. In: Goldenberg $\mathrm{M}$, organizador. $\mathrm{Nu}$ \& vestido. Dez antropólogos revelam a cultura do corpo carioca. Rio de Janeiro: Editora Record; 2002. p. 19-40.

17. Bourdieu P. Remarques provisoires sur la perception sociale du corps. Actes Rech Sci Soc 1977; 14:51-4.

18. Rubin H, Rubin I. Qualitative interviewing. The art of hearing data. London: Sage Publications; 1995.

19. Seale C, Filmer P. Doing social surveys. In: Seale C, editor. Researching society and culture. London: Sage Publications; 1998. p. 125-45.

20. Queiroz, M. Saúde e doença: um enfoque antropológico. Bauru: Edusc, 2003.

21. Herzlich C. A problemática da representação social e sua utilidade no campo da doença. Physis 1991; 1:23-36.

22. Minayo MC. O desafio do conhecimento. Pesquisa qualitativa em saúde. São Paulo: Editora Hucitec; 2007.

23. Richards L. Using $\mathrm{N}$ vivo in qualitative research. Melbourne: QSR International; 2002.

24. Courtine JJ. Os Stakhanovistas o narcisismo: body-building e puritanismo ostentatório na cultura americana. In: Sant'anna DB, organizador. Políticas do corpo. São Paulo: Estação Liberdade; 1995. p. 39-48.

25. Le Breton D. Adeus ao corpo. São Paulo: Editora Papirus; 2003.

26. Luz MT. Novos saberes e práticas em saúde coletiva. São Paulo: Editora Hucitec; 2003.

27. Kimmel MS. A produção simultânea de masculinidades hegemônicas e subalternas. Horizontes Antropológicos 1998; 9:103-17.

28. Klein A. Little big men. Bodybuilding subculture and gender construction. Albany: State University of New York Press; 1993.

29. Costa JF. O vestígio e a aura. Rio de Janeiro: Editora Garamond; 2004.

Recebido em 22/Jul/2008

Versão final reapresentada em 29/Out/2008

Aprovado em 04/Nov/2008 